\title{
Miniaturized UWB elliptical patch antenna for skin cancer diagnosis imaging
}

\author{
Sameer Alani ${ }^{1}$, Zahriladha Zakaria ${ }^{2}$, A. Ahmad ${ }^{3}$ \\ ${ }^{1,3}$ Centre for Advanced Computing Technology (C-ACT), Faculty of Information and Communication Technology, \\ Universiti Teknikal Malaysia Melaka (UTeM), Malaysia \\ ${ }^{2}$ Centre for Telecommunication Research and Innovation (CeTRI), Faculty of Electronic and Computer Engineering, \\ Universiti Teknikal Malaysia Melaka (UTeM), Malaysia
}

\begin{tabular}{l}
\hline \hline Article Info \\
\hline Article history: \\
Received Jun 25, 2019 \\
Revised Oct 10, 2019 \\
Accepted Oct 20, 2019 \\
\hline
\end{tabular}

Keywords:

Biomedical imaging Elliptical patch antenna Microstrip antenna Microwave imaging Skin cancer UWB antenna

\begin{abstract}
The biomedical imaging shows promising results in many applications such as protein characterization and cancer detection using non-ionizing radiation. Skin cancer is one of the most common types of cancer because it is exposed by sun rays during the day. Many techniques have been offered to detect the tumor in the early stage such as ultrasonic and MW imaging. However, most of these studies showed a large printing area with lower BW so as the low resolution. To overcome these drawbacks, a new low profile UWB elliptical patch antenna with high performance is designed on PTFE as a substrate. Then a layer of Indium Tin Oxide (ITO) applies to improve the antenna radiation characteristics. The proposed antenna has a broad BW from $3.9 \mathrm{GHz}$ to $30 \mathrm{GHz}$ along with a resonance at $2.4 \mathrm{GHz}$. Furthermore, the antenna presents a maximum gain of $7.3 \mathrm{~dB}$, maximum directivity of 7.78 $\mathrm{dBi}$, the maximum radiation efficiency of $92 \%$, and consistent, stable radiation pattern throughout the frequency band. Besides, the time-domain characteristics show that the antenna can be a suitable candidate for microwave imaging of skin cancer.
\end{abstract}

Copyright $@ 2020$ Institute of Advanced Engineering and Science. All rights reserved.

\section{Corresponding Author:}

Sameer Alani,

Centre for Advanced Computing Technology (C-ACT),

Faculty of Information and Communication Technology,

Universiti Teknikal Malaysia Melaka,

Hang Tuah Jaya, 76100 Durian Tunggal, Melaka, Malaysia.

Email: itsamhus@gmail.com

\section{INTRODUCTION}

Microwave technology developed fast in both biomedical imaging and satellite communications with promising potentials. For example, they were used in quality control, protein characterization, pharmaceutical, cancer detection using non-ionizing radiation, and satellite communications integrated with solar cells [1,2]. Skin cancer is one of the most general kinds of cancer among all types of cancer throughout the world. It is because the human body is exposed to sunlight during the day a lot. Thus, the chance for the human body to get affected by the sunlight and its destructive rays is high, and the cancerous cell formation increases since the skins are getting affected by the UV. The UV could harm the skin cells when the body exposed for an extended period during the day. Many imaging systems and devices were applied for vast applications that are listed such as localization, finding concealed threats like weapons in airport, security and surveillance, and medical imaging. One of the exciting applications used ultra-wideband technology for biomedical imaging, notably to differentiate between unhealthy and healthy tissue such as cancer detection in skin and chest [3-5].

The UWB technology shows promising outcomes since it can give a wide BW with lower power [6]. Besides, it can be profitable for data communication in low range with a high rate, and even it is 
capable of being suitable for radar communications. The applied hardware and software for UWB technologies made many possibilities to achieve larger BW required for having better detection and higher resolution in the detection process [7]. However, designing a compact size antenna with wide bandwidth is a serious challenge. Furthermore, a variety of properties possess by UWB technologies such as signals with no ionizing impacts, cheap and penetration capability to different materials, making these techniques an ideal choice for several applications related to human health [7-11]. Although many tomographic methods such as X-ray-based computed tomography (CT), ultrasound scanners, and nuclear magnetic resonance imaging (known as MRI) were exploited in clinics and hospitals to get an image of living tissue, they couldn't fulfill the expectations utterly. The above tomographic techniques have mostly shown long scanning and computing time [12]. The biopsy technique was one of the most common techniques applied for skin cancer diagnosis in which one part of the skin liquidate and then sent to the lab for examination. The problem with this method was the long period of getting the result as a week [13].

MW imaging used to differentiate the material with different dielectric properties. For instance, they employed to detect the differentiation between the dielectric properties of healthy and unhealthy tissues to detect cancerous cells in the skin. Usually, our skin has three layers known as epidermis, dermis, and the external one, and their thickness varies between 0.1 and $0.5 \mathrm{~mm}$, the outermost layer is called the epidermis. The epidermis owns an external part which is Stratum Corneum (SC) with varying thickness of 15 and $150 \mu \mathrm{m}$ [14].

Several works were performed for skin cancer imaging in a different range of frequencies like MW, millimeter waves (mm-wave), and Terahertz ( $\mathrm{THz})$ waves for various parts of the body such as skin and breast [14]. All those dielectric properties used in the imaging system were to be used in the detection system, like for skin cancer, especially in millimeter waves. Due to the longer wavelength of MW frequency range, MW imaging systems were used widely for medical applications, especially cancer diagnoses. The frequency range of $300 \mathrm{MHz}-10 \mathrm{GHz}$ was used, and some works used a shorter wavelength in the frequency range of 30-300 GHz [15]. In addition to that, the appropriate wavelengths used for imaging of human body parts were in a regime between $0.6 \mathrm{~mm}$ and $1.2 \mathrm{~mm}$ [16]. Each layer of skin is affected by these wavelengths. On the other hand, these layers are the layers that the chance of being attacked with cancerous cells is high. This paper is configured as follows: a brief introduction is given in Section 1. Then the UWB. Afterward, the proposed antenna design and results are demonstrated in Section 2 and 3, respectively. Finally, the paper concludes in Section 4.

\section{RESEARCH METHOD}

The elliptical patch is considered as the most common and the simplest shape of microstrip patch antenna applied for UWB applications which help in having a high percentage of fractional BW (FBW) [17-19]. The proposed antenna comprises a vertical elliptical patch as shown in Figure 1, a truncated ground, stubs, shorting pins for loading, and square shape EBG structure. A conventional elliptical patch is designed at the center frequency of $15 \mathrm{GHz}$ initially using the transmission line (TL) method and the equations presented in [20] to get the total dimensions of the substrate and the patch. The patch is a vertical elliptical microstrip patch antenna with specifications of semi-major axis $b$ and semi-minor axis a, the foci are at $x= \pm c$ and $c$ determine the foci of the elliptical patch $[16,20]$. The antenna is designed on three substrate

layers

a Roggers $5880\left(\varepsilon_{r}=2.2, \mathrm{~h}=0.787 \mathrm{~mm}\right)$, a PTFE layer $\left(\varepsilon_{r}=2.55, \mathrm{~h}=2.5 \mathrm{~mm}\right)$ as a cover, and layer of ITO ITO $(\mathrm{h}=0.1 \mu \mathrm{m})$ in between. After investigating the results from the conventional antenna, the antenna performances should be improved as well as having resonance at lower bands while not to increase the antenna dimensions.

Hence, to enhance the BW and reduce the stopbands level in reflection coefficient result which might occur due to the size reduction and changing the materials, the GND is truncated to the length of almost $\lambda / 8$ as shown in Figure 1. Afterward, to transfer the working BW to the lower band and keep the size unchanged at the same time the antenna is loaded with a stub connected to the junction of the feed line and the patch [20]. The total length of this stub is designed based on the frequency and the wavelength at 2.4 GHz. Adding this stub to the antenna benefits us to resonate at a free licensed band as ISM. Unfortunately, the radiation efficiency is decreased due to the surface wave and the coupling when this stub is added. Hence, a technique should be applied to suppress these surface waves and compensate for this decrement. As aforementioned, the stub length should be related to the resonance at the lower band that it is desired to resonate at $2.4 \mathrm{GHz}[7,17]$. Figure 2 shows the current distribution around the stub to prove the resonance at $2.4 \mathrm{GHz}$. Apart from the surface wave and negative coupling, some stopbands occurred in BW after connecting this stub. These stopbands are removed by applying the Electronic Band Gap (EBG) structure as shown in Figure 1. 


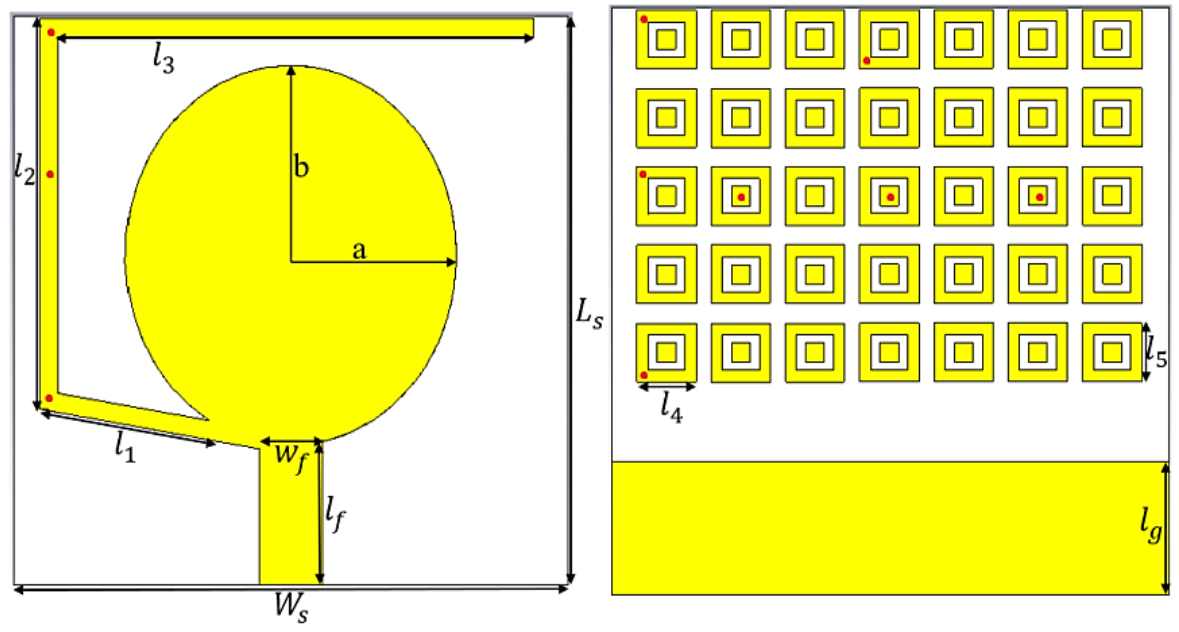

Figure 1. Proposed antenna prototype (the reed points are shown the shorting point locations)

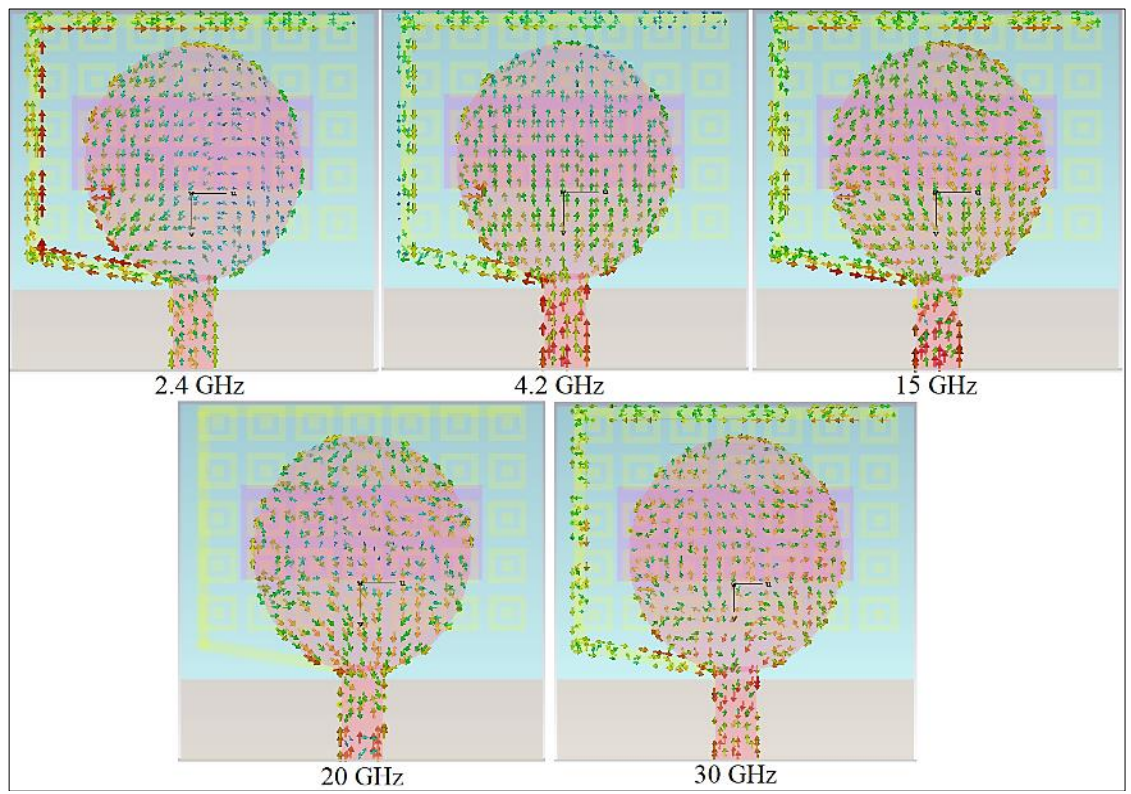

Figure 2. The surface current distribution

By adding the rectangular EBG structures, both frequency band and the single resonance is shifted to the lower band; in addition to that, the stopbands suppressed as well [21-23]. Based on the surface current distribution of the patch and the feed line, the EBG structure is located symmetrically to have a symmetrical radiation pattern. Furthermore, after checking the results achieved from the proposed antenna, it is noticed that despite applying the EBG structure, still, some stopbands remained on the BW. The antenna loads with shorting pins to exclude them as well as decrease the surface waves (the red points in Figure 1.). These shorting pins have connected the patch to EBG structures according to the current flow around the stubs and the EBG structures and the locations with net E-fields [24].

\section{RESULTS AND ANALYSIS}

After applying the TL method, the obtained antenna dimensions for a typical rectangular patch antenna based on the lowest resonance $(2.4 \mathrm{GHz})$ should be around $125 \times 125 \mathrm{~mm}^{2}$. Furthermore, the monopole antenna for the length of $\lambda, \lambda 2$, and $\lambda / 4$ are $125 \mathrm{~mm}, 62.5 \mathrm{~mm}$, and $31.25 \mathrm{~mm}$, respectively (to show the dimensions of monopole antenna based on the wavelength). The final dimensions and values for 
each parameter in Figure 1. is presented in Table 1. Each parameter is optimized to get the best result of the radiation characteristics of the antenna. However, the total dimensions of the antenna are less than $\lambda / 4$, but good stability is achieved due to applying EBG and proper loading of the antenna. Another technique that used here to improve the antenna performances is adding a layer of ITO between the antenna and the cover layer of PTFE.

Table 1. Proposed Antenna Final Dimensions

\begin{tabular}{cccccc}
\hline Param $(\mathrm{mm})$ & value & Param $(\mathrm{mm})$ & value & Param $(\mathrm{mm})$ & value \\
\hline $\mathrm{L}_{\mathrm{s}}$ & 15 & $\mathrm{~L}_{4}$ & 1.6 & $\mathrm{a}$ & 4.5 \\
$\mathrm{~L}_{1}$ & 5 & $\mathrm{~L}_{5}$ & 1.5 & $\mathrm{~b}$ & 5 \\
$\mathrm{~L}_{2}$ & 10.25 & $\mathrm{~L}_{f}$ & 3.8 & $\mathrm{~W}_{\mathrm{s}}$ & 15 \\
\hline
\end{tabular}

Figure 3 illustrates the reflection coefficient result of the antenna for each step of the design. The results presented in Figure 3 shows that when the antenna has its conventional structure, several stopbands occurred in the BW. Then, the truncated GND and the cover layer are added to the antenna to make passband, especially at the lower than $20 \mathrm{GHz}$. Afterward, the ITO layer is added to shift the frequency to the lower band, increase the radiation efficiency, and the impedance BW of the antenna (the gap between the EBG rectangular structures, the shorting pins, and the stub should be adjusted appropriately not to enhance the unwanted coupling).

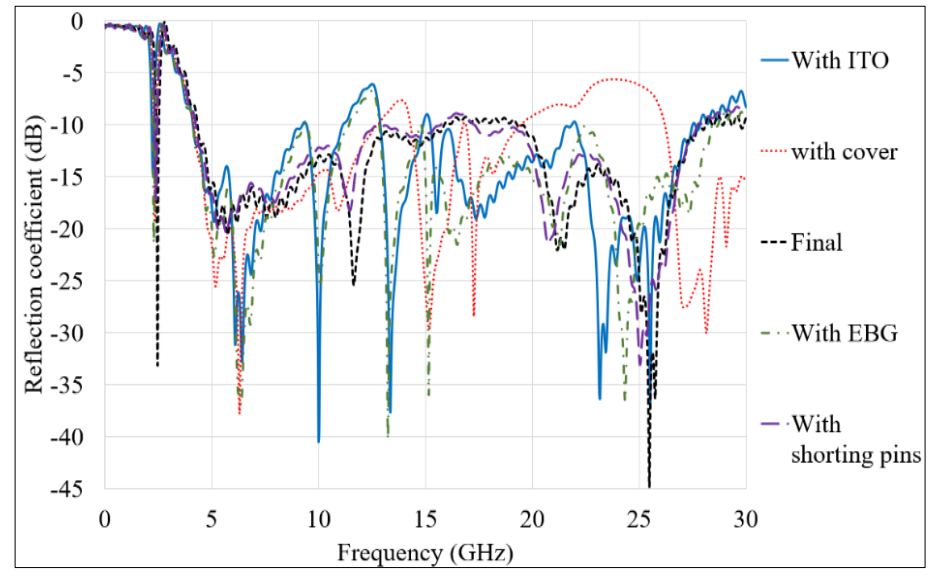

Figure 3. Reflection coefficient result of the proposed for each step

Although the band shifted to the lower band, some stopbands occurred due to the expected coupling. Hence, the rectangular EBG structure added at the back of the antenna to suppress the back radiation, reduce the SAR value, and improve the radiation efficiency of the antenna through the inductive and capacitive effects that exist in every periodic structure (Like PBG, HIS, FSS) [25-28]. After degrading the undesired stopbands and extinguish them, the stub is connected to the EBG on the other side of the antenna using shorting pins (red points in Figure 1.). The other stopbands removed by loaded the antenna by these shorting pins as well. Loading the proposed antenna by these pins, suppress both the stopband and surface waves. Therefore, the antenna performances improved as presented in Figure 4 (simulation results). In addition, after fabricating the antenna as shown in Figure 5 and perform the measurement, both the simulated and measured reflection coefficient results of the proposed antenna show a proper agreement in Figure 4.

Figure 6 shows the simulated and measured far-field radiation pattern of the antenna for the whole frequency band. The radiation patterns are measured using a SATIMO Starlab near-field measurement system. While each antenna works over a large frequency range, the patterns are measured at each pole and the lower and higher end of the ultra-wide BW to show the overall behavior at the low, mid, and highfrequency ranges. It is demonstrated that the antenna attained a stable pattern for most of the band and a good agreement exists between the simulated and measured patterns. Since the antenna pattern didn't change for most of the band, only those frequencies which have alleviated a bit from its previous frequencies presented. Furthermore, the radioiron pattern is mostly changed in less than 30 degrees. 
Figure 7 shows the simulation and measurement setup of the array antennas. In simulation and measurement, all the antennas are sending and receiving UWB signals. Each antenna array is located on a layer of skin, muscle and bone with the thickness of $2 \mathrm{~mm}, 6.5 \mathrm{~mm}$ and $13.5 \mathrm{~mm}$, respectively. For more explanation, Figures 8 and 9 present the simulated reflection coefficient and transmission coefficient results of the proposed antenna when they are located on the skin, muscle, and bone. It illustrates that the antenna's reflection coefficient results in the skin are not altered a lot in comparison with the result in the air except a stopband produced after $20 \mathrm{GHz}$ to $24 \mathrm{GHz}$. Besides, the lower end of the UWB antenna is shifted to a higher band slightly. Moreover, the transmission coefficient of the antenna shows functional coupling and isolation between antenna arrays on the skin, along with muscle and bone. The alteration between the results in air and skin is because of higher permittivity and the physical structure of the skin, muscle, and bone as compared to free space.

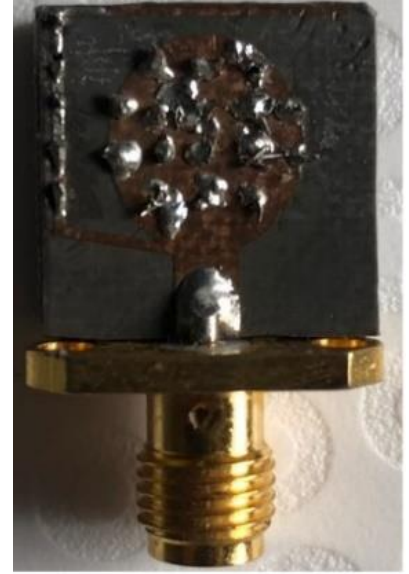

Figure 4. The fabricated prototype of the antenna

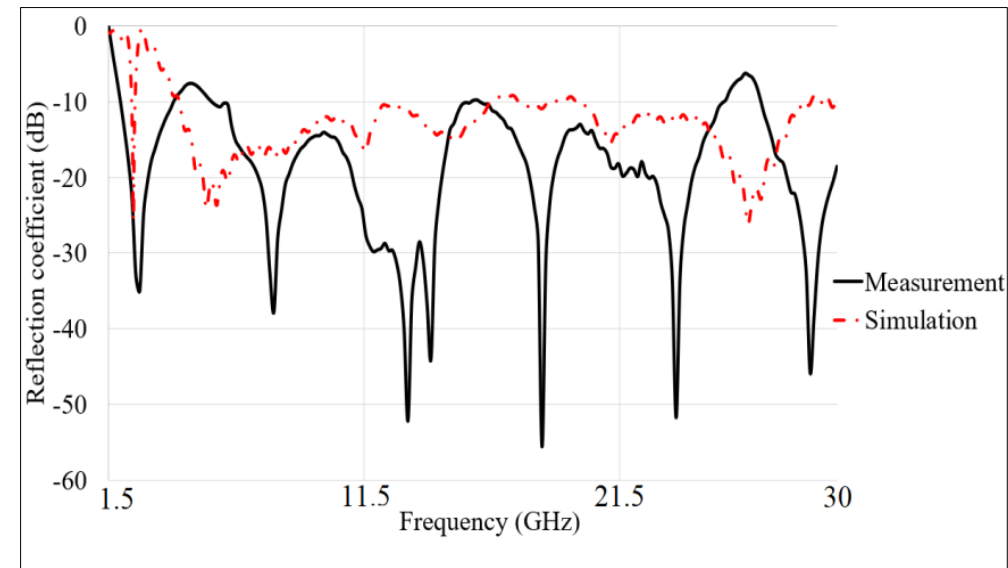

Figure 5. Simulated and the measurement result of the antenna
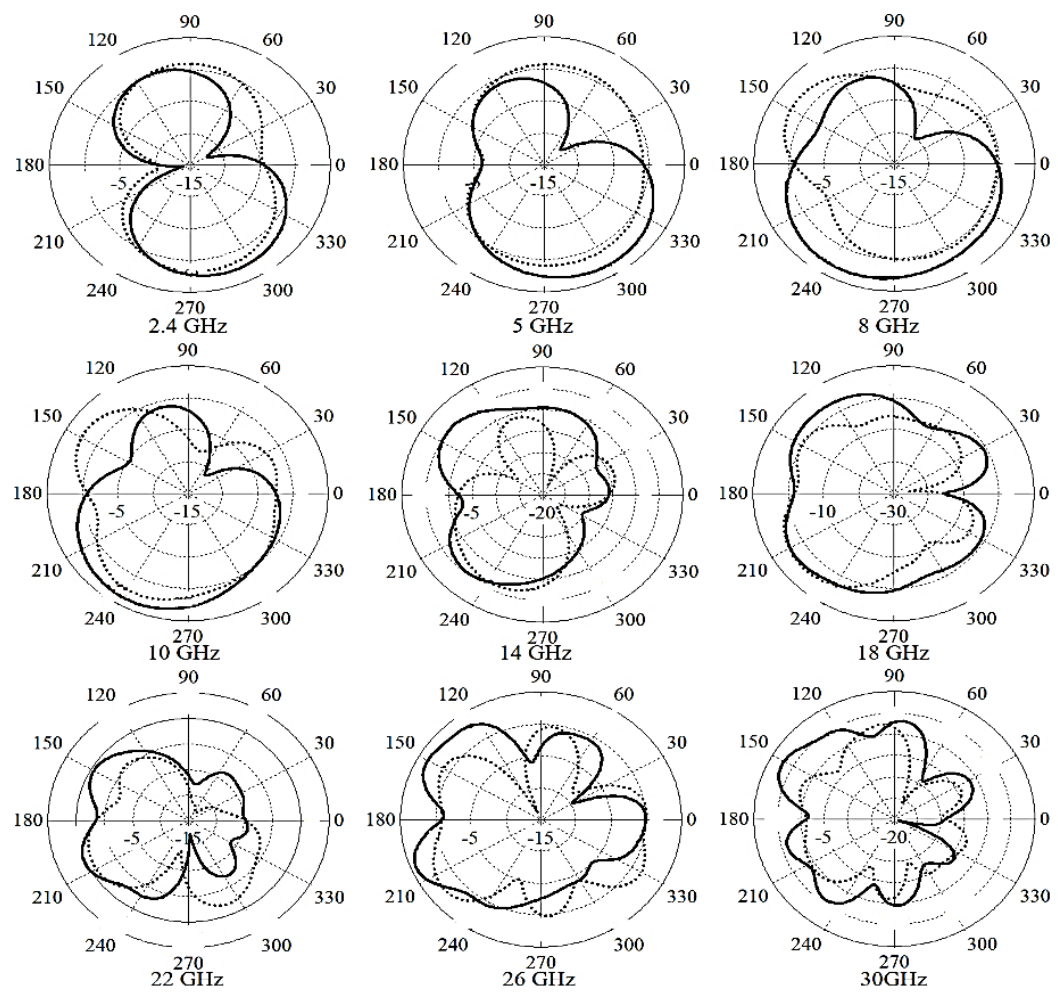

Figure 6. Simulated (solid line) and measured (dashed line) radiation pattern of the proposed antenna 


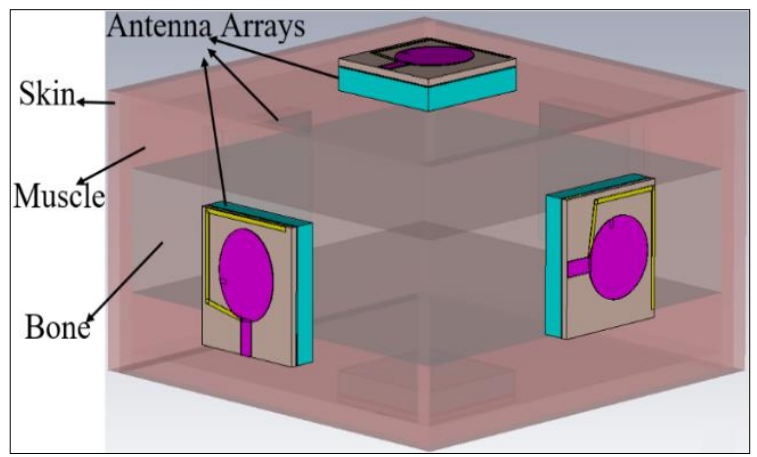

Figure 7. Simulation setup of the array antennas

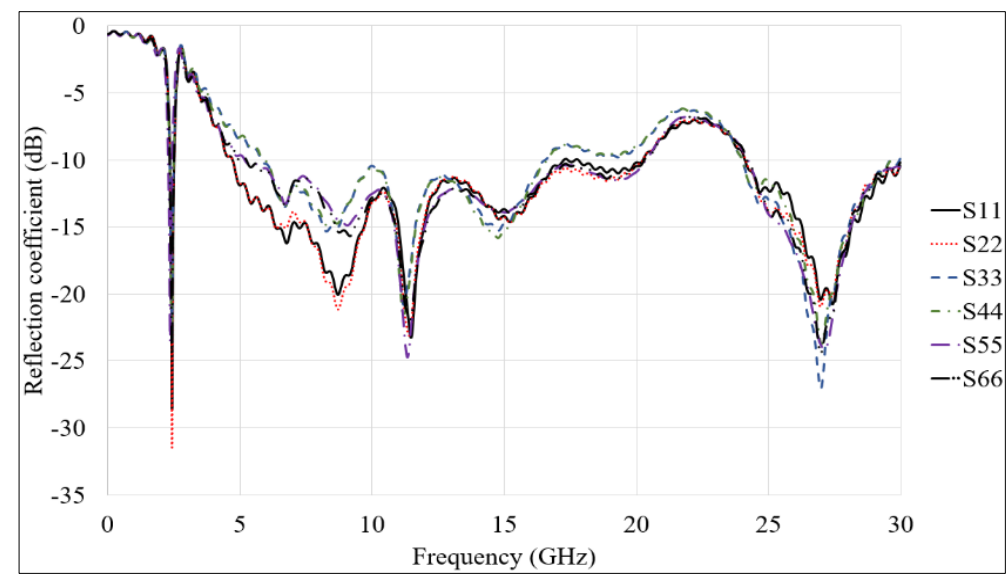

Figure 8. Simulated $\mathrm{S}_{11}$ result of the antenna arrays when they face skin, muscle, and bone

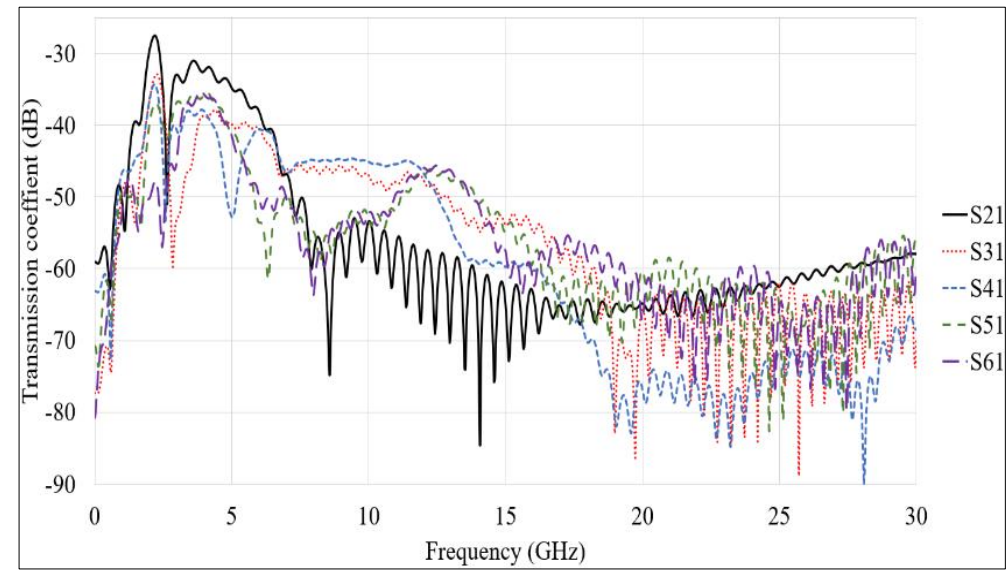

Figure 9. The simulated $S_{21}$ result of the antenna and five arrays around it when they face the skin, muscle, and bone

\section{CONCLUSION}

An elliptical patch antenna is printed and presented in this paper. The proposed antenna has a smaller printing area and better performances in comparison with the recent works. The proposed antenna obtained a broad BW from $3.9 \mathrm{GHz}$ to $30 \mathrm{GHz}$. Thus, it can achieve high resolution since it has wide BW and most of the high-frequency bands are in working BW of the proposed antenna. In addition to that, the proposed antenna achieved a maximum gain of $7.3 \mathrm{~dB}$ and the maximum directivity of the $7.78 \mathrm{dBi}$. 
The radiation efficiency of the antenna shows the maximum percentage up to $92 \%$ after using the ITO layer. Due to the outstanding outcome of the antenna even with small dimensions $(15 \mathrm{~mm} \times 15 \mathrm{~mm})$, it can work for medical imaging (skin cancer detection) in $\mathrm{GHz}$ band as well as the satellite communications (solar cells integration).

\section{ACKNOWLEDGEMENTS}

The authors would also like to thank Centre for Research and Innovation Management (CRIM), UTeM's research grant JURNAL/2018/FKEKK/Q00001 and Universiti Teknikal Malaysia Melaka (UTeM) for their encouragement and help in supporting this work.

\section{REFERENCES}

[1] D. Auston, "Picosecond Optoelectronic Switching and Gating in Silicon," Appl. Physics Letters, vol. 26, no. 3, pp. $101,2008$.

[2] T. Saeidi, I. Ismail, A. R. H. Alhawari, A. Sali, and A. Ismail, "High Gain Dual-Band Couple Feed Transparent $\mathrm{THz}$ Antenna for Satellite Communications," in IEEE Asia-Pacific Conference on Applied Electromagnetics, APACE 2016, 11-13 December 2016, Langkawi, Kedah, Malaysia, pp. 11-15.

[3] Lieber C. A., Majumder S. K., Billheimer D., et al., "Raman Microspectroscopy for Skin Cancer Detection in Vitro," J. Biomed. Opt., vol. 13, no. 2, pp. 024013, 2008.

[4] Lassau N., Mercier S., Koscielny S., et al., "Prognostic Value of High-Frequency Sonography and Color Doppler Sonography for the Preoperative Assessment of Melanomas," AJR. Am J. Roentgenol., vol. 172, pp. 457-461, 1999.

[5] O. Abuzaghleh, B. D. Barkana, and M. Faezpour, "Noninvasive Real-Time Automated Skin Lesion Analysis System for Melanoma Early Detection and Prevention," Int. Journal of Transitional engineering in Health and Medicine, vol 3, 2015.

[6] A. El F, S. Bri, and A. Saadi, "UWB Antenna with Circular Patch for Earley Breast Cancer Detection," TELKOMNIKA (Telecommunication Comput. Electron. Control., vol. 17, no. 5, 2019.

[7] T. Saeidi, I. Ismail, W. P. Wen, and A. R. H. Alhawari, "Ultra-Wideband Antennas for Wireless Communication Applications," International Journal of Antennas and Propagation, vol. 2019, 25 pages, 2019.

[8] Wenyi S., Z. Beibei and W. G. (2005). Early Breast Tumor Imaging Via UWB Microwave Method: Study on Multi-target Detection. Antennas and Propagation Society International Symposium, 2005 IEEE, 3A, 835-838.

[9] M. Y. Zeain, M. Abu, Z. Zakaria, H. S. M. Sariera, and H. Lago, "Design of helical antenna for wideband frequency," Int. J. Eng. Res. Technol., vol. 11, no. 4, pp. 595-603, 2018.

[10] H. Sariera, Z. Zakaria, A. A. M. Isa, and R. Alahnomi, "A Review on monopole and dipole antennas for in-building coverage applications,” Int. J. Commun. Antenna Propag., vol. 7, no. 5, pp. 386-396, 2017.

[11] H. S. M. Sariera, Z. Zakaria, and A. A. M. Isa, "Broadband CPW-Fed Monopole Antenna for Indoor Applications," J. Telecommun. Electron. Comput. Eng., vol. 10, no. 2, pp. 31-34, 2018.

[12] M. E. Bialkowski, "Ultra-Wideband Microwave System with Novel Image Reconstruction Strategies for Breast Cancer Detection," In Microwave Conference (EuMC), European, 537-540, 2010.

[13] P. B. Ramesh Garg, "Microstrip Antenna Design Handbook," 2000.

[14] S. Shrestha, M. Agarwal, J. Reid, and K. Varahramyan, "Microstrip Antennas for Direct Human Skin Placement for Biomedical Applications," PIERS Proceedings, Cambridge, USA, July 5-8, 2010.

[15] Ruth M.Woodward,nwVincent P.Wallace,n Richard J. Pye,z Bryan E. Cole,n Donald D. Arnone,n Edmund H. Linceld,w and Michael Pepper, "Terahertz Pulse Imaging of ex vivo Basal Cell Carcinoma", THE JOURNAL OF INVESTIGATIVE DERMATOLOGY, 2003, 302-304.

[16] H. Hong, J. Sun, and W. Cai1, "Anatomical and Molecular Imaging of Skin Cancer," Dove Medical Press Ltd., Clinical, Cosmetic and Investigational Dermatology, 2008.

[17] H. M., Jafari, M. J. Deen, S. Hranilovic, and N. K. Nikolova, "A Study of Ultrawideband Antennas for Near-field Imaging," IEEE Trans. Antennas and Propag., vol. 55, no. 4, pp. 1184-1188, 2007.

[18] M. F. Ain, Y. M. Qasaymeh, Z. A. Ahmad, M. A. Zakariya, and U. Ullah, "An Equivalent Circuit of Microstrip Slot Coupled Rectangular Dielectric Resonator Antenna," Progress In Electromagnetics Research Symp. Proc., At KL Malaysia, pp. 1837-1840, March 2012.

[19] V. Sharma, V. K. Saxena, and K. B. Sharma, "Radiation Performance of an Elliptical Patch Antenna with Three Orthogonal," Romanian Journal of Information Science and Technology, vol. 14. no. 2, 123-130, 2011.

[20] S. Latif, D. Flores-Tapia, S. Pistorius, and L. Shafai, "A Planar Ultrawideband Elliptical Monopole Antenna with Reflector for Breast Microwave Imaging,” Microw. Opt. Technol. Lett., vol. 56, no. 4, pp. 808-813, 2014.

[21] Shweta Yadav, et al. "Design of Dual Band Sawtooth Patch Antenna Using PBG Structure", 2015 2nd International Conference on Signal Processing and Integrated Networks.

[22] N. Mohammedi, S. Zaiter, and R. Oussaid, "Theoretical Study of PBG Materials as Substrates to Enhance Antenna Performance," IEEE, pp. 4799-3824, 2014.

[23] T. Saeidi, I. Ismail, A. R. H. Alhawari, and W. P. Wen, "Near-field and far-field investigation of miniaturized UWB antenna for imaging of wood," AIP Advances, Volume 9, Issue 3. 
[24] Tale Saeidi, Idris Ismail, Wong Peng Wen, and Adam R. H. Alhawari, "Ultra-Wideband Elliptical Patch Antenna for Microwave Imaging of Wood”, International Journal of Microwave and Wireless Technologies, 2019.

[25] S. Elajoumi, A. Tajmouati,J. Zbitou, A. Errkik, A. M. Sanchez, M. Latrach, "Bandwidth Enhancement of Compact Microstrip Rectangular Antennas for UWB Applications,” TELKOMNIKA, vol.17, no.3, pp.1559-1568, June 2009.

[26] A. Alshabo, Peter J. Vial, M. Ros, D. Stirling, and M. A. B. Sidik, "Ultra-Wideband Noise Channel Measurement using a Vector Network Analyzer," Proceeding of International Conference on Electrical Engineering, Computer Science and Informatics (EECSI 2014), Yogyakarta, Indonesia, 20-21 August 2014.

[27] R. H. Thaher and N. B. Hassan, "Proposed P-shaped Microstrip Antenna Array for Wireless Communication Applications," TELKOMNIKA, vol. 16, no. 6, pp. 2597-2607, December 2018.

[28] I. H. Idris, M. R. Hamid, K. Kamardin, and M. K. A. Rahim, "Wide to Multiband Elliptical Monopole Reconfigurable Antenna for Multimode Systems Applications," TELKOMNIKA, vol. 17, no. 4, pp. 1663-1669, August 2019.

\section{BIOGRAPHIES OF AUTHORS}

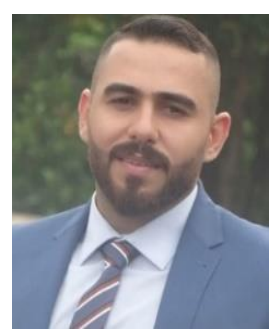

Sameer Alani was born in Iraq, in 1989. He received the B.S. degree in computer engineering and the M.Sc. degree in wireless communication and Computer networking technology from The National University of Malaysia (UKM), in 2017. He is currently pursuing the Ph.D. degree in wireless communication and networking. His research interests include antenna applications, wireless communication, artificial intelligent and networking Technology.

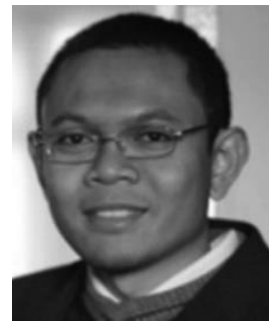

Zahriladha Zakaria was born in Malaysia in 1975. He received the B.Eng. and M.Eng. degrees in electrical and electronic engineering from Universiti Teknikal Malaysia Melaka (UTeM), in 1998 and 2004, respectively, and the Ph.D. degree in microwave engineering from the University of Leeds in 2010. From 1998 to 2002, he was with STMicroelectronics, Malaysia, where he was a Product Engineer. He is currently a Professor and a Coordinator with the Centre for Telecommunication Research and Innovation, Faculty of Electronic and Computer Engineering, (UTeM), where he teaches electronic system, communication principles, microwave engineering, wireless communications, and signal processing. His research interests include variety of microwave devices development, such as planar and non-planar microwave filters, resonators, amplifiers, and antennas. He also investigates data communication and radio wave propagation in wireless communication systems. He has published more than 100 scientific papers in journals, proceedings, and book-chapters. He holds eight intellectual property rights and he has received several awards, including Gold Medal during several research and innovation exhibitions at the national and international level, such as UTeMEX 2012, 2013 and 2015, Malaysia Technology Expo (MTE 2012-2014 and 2016), ITEX 2016, the International Trade Fair Ideas Inventions New Products (iENA 2012), Nuremberg, Germany, and the Seoul International Invention Fair (SiiF 2013), Seoul, South Korea.

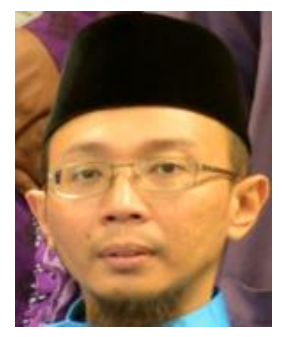

Asmala bin Ahmad received B.App.Sc in Geophysics from Universiti Sains Malaysia (USM) in 1996, MSc. in Land Surveying (Remote Sensing) from Universiti Teknologi Malaysia (UTM) in 2001 and $\mathrm{PhD}$ in Applied Mathematics (Remote Sensing) from University of Sheffield, United Kingdom in 2012. He is currently an associate professor at the Faculty of Information and Communication Technology, Universiti Teknikal Malaysia, Melaka (UTeM). He is also the manager for Centre for Advanced Computing Technology (C-ACT), UTeM. His research interest includes remote sensing, image processing, artificial intelligence and applied mathematics. 